1 Universidade Federal de São Paulo (Unifesp) - São Paulo (SP), Brasil.

barros.lluciana@gmail.com

\section{Entre a 'grande política' e os autogovernos dos Agentes Comunitários de Saúde: desafios da micropolítica da atenção básica}

\author{
Between the 'great politics' and the self-government of Community \\ Health Agents: the challenges of micropolitics in Primary Health \\ Care
}

Luciana Soares de Barros ${ }^{\mathbf{1}}$ Luiz Carlos de Oliveira Cecílio'

DOI: 10.1590/0103-110420195601

RESUMO Investigação qualitativa que teve como foco o processo de trabalho dos Agentes Comunitários de Saúde (ACS), na busca de compreender como eles operam as suas práticas e como constroem relações no território e na Unidade Básica de Saúde (UBS). Foi realizada observação participante em seis UBS da região metropolitana de São Paulo por dez meses. Para a análise do material, foi utilizado o conceito de 'planos de visibilidade', constituídos por cenas registradas em diário de campo pelo pesquisador, os quais permitiram emergir questões relativas à recusa da população; à violência e narcotráfico no território e ao difícil manejo do segredo da comunidade. Além disso, evidenciou-se como o ACS tem-se tornado um ‘trabalhador multiuso' nas UBS, que pensa sua ocupação em caráter provisório, bem como a sua relação com a racionalização das práticas e com a equipe de saúde. O estudo evidenciou um trabalhador em mutação, que reproduz práticas biomédicas e burocratizadas, o que pode desfigurar o seu papel enquanto elo da comunidade, mas que também consegue ser bastante criativo, (re)inventando permanentemente suas práticas, de modo mais complexo do que prescrito nas formulações originais da política de saúde, em função, entre outras coisas, dos problemas que enfrenta nos territórios em que atua.

PALAVRAS-CHAVE Agentes Comunitários de Saúde. Atenção Primária à Saúde. Pesquisa qualitativa.

\begin{abstract}
This investigation focus on the work process of Community Health Agents (ACS) as an effort to understand how they operate their practices, give meaning to their work, and establish relationships in a territorial context and the Basic Health Unit (BHU). For this purpose, we carried out participant observations in six BHU along ten months. For the analysis, we built the concept of 'visibility plans' referent to the ACS's work dimensions, not always immediately visible, as a sensitive coexistence with many forms of violence and drug trafficking in the territory, the difficult management of the community's secrecy, and even the population's refusal regarding household visits, a central component to their action. It has also been demonstrated how the ACS have become a sort of 'multitask worker' within the HCC in a precarious or provisional nature, aside from the often difficult relationship with the health care team. A changing worker has been revealed reproducing biomedical and bureaucratic practices, which may disfigure their bonding role with the community, but who also permanently (re)invents their practices in a more complex way than prescribed in the original formulations of health policies due to, among other factors, the complexity of the territories where they are active.
\end{abstract}

KEYWORDS Community Health Workers. Primary Health Care. Qualitative research. 


\section{Introdução}

Os Agentes Comunitários de Saúde (ACS) têm sido considerados, ao longo dos anos pelo Ministério da Saúde (MS) ${ }^{\mathbf{1}, 2}$, e em vários trabalhos ${ }^{3-5}$, como fundamentais para a viabilização de novos modos de organizar os cuidados primários em saúde.

O contingente de ACS em atividade, em 2017 no Brasil, era de quase 265 mil, atuando em 5.500 municípios, o que correspondia a uma cobertura de quase $67 \%$ da população brasileira ${ }^{6}$.

Desde que surgiram no cenário do Sistema Único de Saúde (SUS), sua trajetória institucional tem sido marcada por desafios e lutas no que se refere à sua institucionalização, e pela busca por melhores condições de trabalho. Afinal, qual a 'identidade' do ACS?

É possível identificar as atribuições dos ACS, conforme definido na Política Nacional de Atenção Básica (PNAB), em duas dimensões principais: uma mais técnica, relacionada com $\mathrm{o}$ atendimento às famílias, intervindo para a prevenção de agravos e monitoramento de grupos prioritários e/ou com problemas específicos, e outra, de cunho mais político, de apoio à organização da comunidade e transformação das condições de vida da população ${ }^{3}$. É o que será denominado no texto de a 'grande política', qual seja, as diretrizes oficiais para orientar a atuação desse trabalhador.

É possível verificar alguns avanços do ponto de vista da institucionalização do trabalho do ACS no SUS, em especial a partir da publicação da Lei $n^{\circ} 10.507$ (2002) que regulamentou sua profissão; a Lei n ${ }^{\circ} 11.350$, de 2006, que deliberou sobre o exercício das atividades e o vínculo do ACS e do Agente Comunitário de Endemias (ACE), circunscrevendo sua atuação exclusivamente no âmbito do SUS; e mais recentemente a Lei $\mathrm{n}^{\mathrm{o}}$ 12.994/2014 que prescreveu o vínculo empregatício direto e o piso salarial da categoria.

A Portaria $n^{0} 2.436^{7}$, que estabelece a revisão de diretrizes para a organização da Atenção Básica (AB) no âmbito do SUS, amplia o escopo da sua atuação, atribuindo-lhes ações de saúde tradicionalmente designadas aos técnicos de enfermagem, o que tem levantado preocupações sobre uma possível descaracterização de suas atribuições originais, em particular, o fato de desobrigar a sua inserção na equipe da Estratégia Saúde da Família (ESF) ${ }^{8}$.

Dessa forma, o presente estudo teve como objetivo produzir uma maior aproximação com a micropolítica do trabalho dos ACS, suas práticas, a gestão do seu trabalho e os sentidos que dão para ele, dando visibilidade para elementos presentes no cotidiano de sua atuação na $\mathrm{AB}$, principalmente em cidades maiores, como foi o caso do estudo, que, como veremos, alarga e complexifica, de modo significativo, o que foi pensado como suas atribuições originais.

\section{Material e métodos}

O estudo, de caráter qualitativo, do tipo estudo de caso ${ }^{9-11}$, adotou, como ponto de partida, o foco no plano microssocial ${ }^{12}$, na micropolítica do trabalho vivo ${ }^{\mathbf{1 3}}$. Privilegiaram-se elementos epistemológicos e metodológicos presentes em abordagens como a sociologia reflexiva ${ }^{12,14}$ e no chamado método cartográfico ${ }^{13-15}$, ancorados nos seguintes pressupostos: o reconhecimento de que não existe neutralidade na pesquisa, pelo contrário, o pesquisador faz parte e modifica o campo de pesquisa; que o ato de pesquisar abre questões ao invés de fechá-las, e que a pesquisa não tem pretensões de revelar ou verificar verdades, mas produzir o conhecimento por meio da troca dialógica do pesquisador entre os atores que compõem o campo de pesquisa.

O trabalho de campo, realizado mediante observação participante, foi executado em seis Unidades Básicas de Saúde (UBS), distribuídas em três cidades da região metropolitana de São Paulo, envolvendo uma equipe de seis pesquisadores, incluindo uma coautora do presente artigo. Com uma dedicação de 8 horas a 12 horas semanais durante dez meses (de janeiro a outubro de 2014), os pesquisadores acompanharam os processos de trabalho e cuidado destas 
UBS, produzindo diários de campo a cada visita realizada. Nos diários de campo, eram registradas 'cenas' que chamavam a atenção do pesquisador do dia a dia da UBS e seus diferentes trabalhadores, aquilo que ia transcorrendo durante a presença do pesquisador em campo. Para este estudo, foram recortadas para a análise 'cenas' que diziam respeito aos ACS.

Tais registros feitos em seis UBS diferentes, posteriormente, eram postados em site específico da pesquisa, permitindo que todos os pesquisadores tivessem acesso às observações realizadas nas UBS incluídas no estudo.

Este estudo está vinculado a uma pesquisa contemplada pelo Programa de Pesquisas para o SUS (PPSUS), com financiamento via Fundo de Amparo à Pesquisa do Estado de São Paulo (Fapesp). O projeto de pesquisa foi devidamente aprovado pelo Comitê de Ética em Pesquisa da Universidade Federal de São Paulo, com o parecer $\mathrm{n}^{\circ} 991.265$ e CAAE: 41294814.4.0000.5505.

\section{Análise dos dados}

O material empírico produzido no correr do desenvolvimento do campo, abordando várias dimensões dos cuidados primários em saúde, era apresentado e analisado em seminários de pesquisa envolvendo todos os pesquisadores. Nesses seminários, iam sendo formulados, gradualmente, o que se denominou 'planos de visibilidade'. Apesar de serem unidades diferentes entre si, havia algo em comum entre elas quando se tratava do trabalho do ACS. Cenas que tratavam de situações semelhantes (ocorrências, comportamentos, falas e reflexões etc.), quando conectadas entre si (por proximidade), resultavam em planos de visibilidade. Plano de visibilidade, portanto, é aquilo que emerge do material empírico bruto, quando tal estratégia de tratamento metodológico é adotada. Produzir visibilidades para elementos do cotidiano de trabalho que podem passar desapercebidos, ou não valorizados, inclusive pela gerência da unidade. Visibilidades que emergem da micropolítica do trabalho dos ACS: práticas, invenções, atos de resistência, reflexões, criatividade e produção de novos sentidos para seu trabalho.

Para a elaboração da dissertação que gerou o presente artigo, foi realizada a leitura extensiva de todo o material produzido nos diários de campo, 'extraindo' deles cenas registradas que, de modo mais ou menos direto, traziam informações sobre o trabalho dos ACS. Reiterando: tais planos deram 'visibilidade' para elementos importantes do cotidiano desses trabalhadores nem sempre previstos na formulação da política de saúde e quase nunca levados em consideração pela gestão da unidade.

$\mathrm{Na}$ finalização do processo de pesquisa, foram realizados Seminários Compartilhados (SC) entre pesquisadores e membros das equipes das unidades estudadas, um para cada UBS-campo de pesquisa. Estes SC ocorreram no período de novembro de 2014 a fevereiro de 2015. Não foram definidos, a priori, critérios para determinar quais trabalhadores seriam convidados. No geral, cada SC contou com a presença de quatro a seis representantes das UBS, dentre eles: ACS; enfermeira; profissionais do Núcleo de Apoio à Saúde da Família (Nasf); gerentes, e uma liderança comunitária presente em um dos SC cuja UBS tinha como característica uma forte mobilização popular.

Os critérios que mobilizaram os convites para participação dos SC, de modo geral, tinham relação com o vínculo do pesquisador com o convidado durante o trabalho de campo, e/ou o fato de o trabalhador convidado 'estar presente' em muitos diários de campo, e/ou por seu reconhecimento e legitimidade perante os demais membros da equipe.

Nesses seminários, era realizada uma apreciação conjunta do material empírico produzido durante a investigação. Neles, eram apresentadas algumas cenas registradas durante o trabalho de campo, tendo como principal objetivo ampliar a capacidade do grupo de pesquisa de analisar e compreender o material empírico, abrindo possibilidades de inserção de novas perspectivas e sentidos ainda não valorizados. 


\section{Resultados e discussão: os 'planos de visibilidade'}

Os 'planos de visibilidade' que emergiram no tratamento do material empírico ajudam a reconhecer o quanto a natureza e a produção do trabalho do ACS em sua dimensão micropolítica são mais complexas e contraditórias do que o prescrito pela política de saúde, pela 'grande política', constituindo-se tal constatação, e suas indicações para a gestão local de saúde, o principal resultado do presente estudo.

\section{$O$ fato de o ACS recrutado nem sempre 'ser do território’ é apreciado como positivo pelo ACS}

A formação de vínculo com determinada comunidade e o conhecimento, em princípio, de suas necessidades pelo fato do ACS ser recrutado no seu território de moradia, são apontados como as principais características do ACS como um novo tipo de trabalhador de saúde.

No entanto, e como fato surpreendente, vários $\mathrm{ACS}$ que participaram dos $\mathrm{SC}$ com os pesquisadores apontaram a desvantagem de morar no mesmo território no qual atuam profissionalmente, dada a perda de privacidade, o que, em alguns casos, chega a colocá-los em risco. Para alguns, esse problema chega a ser maior do que as vantagens que adviriam na área de cobertura da unidade de saúde.

A política de saúde diz que a gente tem que morar no território por conta do vínculo. Eu acho que esse é o pior, se não tem vínculo é mais fácil de você saber o que é que você faz independente de onde você mora. Eu morava lá eu não conhecia nem a rua de trás da minha casa, aprendi a conhecer no dia a dia, agora sei nome, número de tudo, de qualquer rua do território, e assim, eles conhecem mais a gente do que a gente [a eles]. Então quem fica mais vulnerável é a gente do que eles. (Seminário Compartilhado da UBS 1).
Essa dimensão trazida por diversos ACS que participaram dos SC alerta sobre as discrepâncias entre as diretrizes oficiais da política de saúde para a atuação e responsabilidades dos ACS, e a micropolítica do seu trabalho, considerando as condições concretas em que atuam; e as surpreendentemente complexas relações que estabelecem com a 'comunidade', quando toda uma ética do trabalho (o segredo, a privacidade, a normalização da vida etc.) é posta de modo tenso e permanente. Aqui, também, estamos diante de um tema importante para o acompanhamento e o apoio da gestão - o que nem sempre acontece -, de modo que os ACS vão tendo que lidar, por conta própria, com desafios nada fáceis para seu trabalho.

Existem situações no território em que os ACS sentem receio de colocarem em risco sua própria integridade física ou a de seus familiares, como em relação ao manejo de segredos. O modo como o ACS lida com os segredos dos usuários comporta algumas possibilidades: há situações em que o ACS abre o segredo para equipe; há situações que ele não abre ou abre, parcialmente, para apenas um membro da equipe; há situações em que ele não sabe o que fazer com o segredo.

Conversa de uma ACS com pesquisadores sobre uma suspeita de abuso sexual de uma criança do território:

Eu não passo na reunião esse tipo de coisa, eu passo para a enfermeira, mas para a equipe não. Porque fica essa coisa que todo mundo conhece todo mundo. (Seminário Compartilhado - UBS 2).

O segredo, portanto, faz parte da vida privada dos cidadãos, de comunidades, bem como do cotidiano dos ACS. Eles são trabalhadores, cuja natureza do trabalho é acessar o privado. $O$ fato de morarem na mesma área em que trabalham possibilita que eles tenham acesso a muitas questões que são invisíveis para a equipe de saúde e que, possivelmente, apenas os ACS terão acesso. Isso acontece ora pela confiança que os moradores depositam neles, pelo vínculo profissional e/ou 
pelo status de vizinhança, ora por serem parte integrante da comunidade por onde os segredos circulam.

Estavam presentes três das equipes da UBS, além da psicóloga do Nasf, as matriciadoras (psiquiatra do Caps-i e Enfermeira do Caps-AD) e eu. No segundo caso, a equipe contou sobre o usuário $C$ : familiares apresentaram o rapaz como violento, e com queixa de 'enxergar faixas pretas e brancas' além de falar sozinho, e a equipe suspeita que ele faça uso de drogas. Preocupada com isso, a enfermeira questionou sua irmã em consulta de pré-natal sobre o relacionamento deles e comportamento do rapaz em casa. A irmã contou para $C$ sobre os questionamentos, e ele ficou irado, foi até a casa da ACS e ameaçou matar a enfermeira. A enfermeira ficou alguns dias sem ir à área, evitando encontrá-lo. Quando o encontro foi inevitável, ela negou ter feito os tais questionamentos, e o rapaz então se desculpou.

A equipe também trouxe o caso de E.C., 56 anos, com diagnóstico de depressão após descobrir as traições do marido. Não quer vir à UBS, pois sente que está agressiva, e contou somente à ACS que pensou em agredir a médica durante consulta. (Matriciamento Saúde Mental - UBS 5)

\section{Convivendo com a recusa}

Visitar as famílias do território uma vez por mês faz parte das prescrições do trabalho dos ACS. No entanto, essa normativa não está necessariamente relacionada com as necessidades e demandas dos usuários. Existem dissonâncias entre a oferta dos ACS nas Visitas Domiciliares (VD) e as expectativas dos usuários, o que pode resultar em recusa às visitas.

Segundo a ACS Bf, o que mais a incomoda é ter que ir todo mês à casa de quem não quer atender, e conta várias situações onde ela tem certeza que tem gente em casa e que não abrem a porta, mandam as crianças atenderem e dizer que a mãe está fora, ou gritam lá de dentro que não tem ninguém. (UBS 4).
Ao chegar à área, o grupo se divide batendo em várias casas ao mesmo tempo. Logo uma senhora aparece na varanda e ao descobrir que são as agentes para falar sobre dengue começa a reclamar, diz que não vai atender, que elas passaram por lá não tem nem 15 dias. A senhora falava da parte de cima da casa, gritando para quem quisesse ouvir e as meninas estavam na rua (as ACS), tentando convencê-la a abrir a porta. Bn e By saíram logo de perto, indo em direção à outra casa e ao passarem por mim, Bn falou: 'Tá vendo. É essa humilhação que a gente passa todo dia. Eu não fico insistindo, não quer a nossa presença não sou eu que vou insistir'. (Em VD com ACS - UBS 3).

Essa dimensão da recusa e humilhação é frequente nas falas dos ACS. Eles precisam, nos seus cotidianos de trabalho, lançar mão de subterfúgios para conseguirem (ou tentarem) adentrar nas casas dos usuários, como fazer ameaça de multa, como foi possível perceber nas observações, ou ocuparem o lugar de mediação para outros acessos na UBS (consulta ou procedimentos por exemplo), ao invés de serem reconhecidos em suas atividades de educação e prevenção em saúde.

O que o material empírico apresenta é que, nesse percurso de mais de duas décadas da implantação do Programa de Agentes Comunitários de Saúde (Pacs) e ESF, os encontros entre ACS e comunidade são múltiplos, e não estão garantidos apenas pelo fato de o ACS residir no bairro de atuação.

\section{Convivendo com o narcotráfico e com a violência}

Outro fator que está intimamente ligado ao cotidiano do ACS é o seu convívio com o narcotráfico e com a violência. Diferentemente da maioria da equipe que mora, muitas vezes, distante da UBS, os ACS estão inseridos nessa realidade e, portanto, precisam criar estratégias para lidar com ela ${ }^{19}$. Tais estratégias passam a funcionar como regras de trabalho compartilhadas entre os ACS, como, por exemplo, adotar 
determinados códigos de conduta, fixarem horário de visita em territórios comandados pelo narcotráfico, ou mesmo naturalizarem determinadas situações que em outros contextos poderiam ser motivo de estarrecimento.

Ela me mostra um galpão com alguns jovens na porta. Conta que ali é ponto de refinação e distribuição de drogas para as 'bocas'. Ela diz de forma natural: 'Eles são tranquilos. Uma vez fui lá e eles ficaram fumando maconha e cheirando cocaína enquanto eu fazia o cadastro do SUS deles'. Conta a história de duas enfermeiras do curso de especialização de PSF e que não conheciam a área: 'São ingênuas. Subiram ali naquele sobrado onde tinha um monte de caras usando drogas pra falar com eles. Numa dessas, esses caras dão uma paulada na cabeça delas e fazem o que querem. Eu avisei pra não fazerem mais isso...'. (VD com ACS - UBS 3).

Em um dos SC (UBS 2), uma ACS expõe: " $a$ gente tá tão acostumado que nem sente mais". É quase uma estratégia de sobrevivência. Diferentemente de grande parte da equipe que retornam para as suas residências ao fim do expediente, muitas vezes distantes da USB, os ACS convivem com essa realidade.

Desse modo, o conceito e o efeito do narcotráfico e da violência operam de modo diferente a depender do lugar que se ocupa: dos pesquisadores; dos profissionais de saúde que moram distante da UBS e do lugar de quem é morador daquele território, como é o caso dos ACS. O lugar que os ACS ocupam na UBS na relação com a população é revelador de outro ponto de vista sobre a violência e sobre o narcotráfico, mais relativizado, mais naturalizado e de maior convivência do que o presente no discurso do restante da equipe e fora do alcance da 'grande política'.

\section{Do ACS militante ao ACS mutante}

A multiplicidade de concepções e entendimentos sobre o ACS e sobre a sua função coloca em evidência as expectativas que ele teria que atender no seu trabalho cotidiano e, por consequência, algumas condições concretas de conformação de uma identidade diante da valorização de um determinado perfil de atuação ${ }^{20}$.

Frequentemente, para que os ACS consigam cumprir todas as demandas atribuídas a eles, não basta desempenhar um conjunto de tarefas prescritas para a função, eles precisam ser uma espécie de 'ACS-militante', desenvolvendo um trabalho que adquire característica de uma 'missão', e isso é esperado deles, em especial, pela gestão.

O pressuposto assumido por alguns autores de que o ACS se configura como a mola propulsora da consolidação do SUS, atuando como ponte e elo da população e com vocação solidária $^{21}$ e tendo uma liderança natural ${ }^{2}$, é gerador de idealizações difíceis de serem manejadas na vida concreta do trabalho.

O discurso recorrente sobre um ACS imaginado ou idealizado parece revelar uma visão romântica sobre esse trabalhador: "Não fazer mais do mesmo; ser diferenciado; ser escolhido a dedo; ter uma alma própria”, como foi possível captar na fala dos trabalhadores das UBS durante a pesquisa. Essa visão parece estar na contramão de um ACS contemporâneo em mutação, um ACS-Mutante, cada vez mais funcionalizado e mais híbrido, um trabalhador 'multiuso' na UBS.

[...] a ACS [T] é a que fica mais tempo na recepção da unidade. Ela falou que não gosta de ficar lá, mas ela ajuda a coordenadora da unidade por que não tem ninguém para ficar. (UBS 1).

Por outro lado, há uma perceptível expectativa dos ACS de ocuparem um 'lugar melhor' no campo da saúde, evidenciada pela busca por ascensão profissional, seja via estudo formal para galgar novas profissões na saúde, seja por tentarem postos de trabalho mais valorizados dentro da UBS22. O 'ser' ACS vai sendo substituído por um 'estar' ACS, especialmente para os trabalhadores mais novos de serviço e de faixa etária. 


\section{ACS como alvo de estratégias racio- nalizadoras da gestão}

O ACS tem seu trabalho cada vez mais pautado por componentes de uma 'ordem construída e contingente', com ênfase na irredutível captura da ação humana a papéis e regras rigidamente estabelecidas e operadas, neste caso, principalmente a partir de metas de produtividade, com aumento das exigências de registros e burocratização das tarefas, que constitui-se como uma das dimensões da crescente racionalização das práticas de saúde ${ }^{23-25}$.

Pesquisadora pergunta a ACS quanto tempo por dia ela gasta com o preenchimento de papéis:

Ah, umas 2 ou 3 horas por dia, isto porque eu não preencho tudo certinho, ninguém dá conta e eles acham que este monte de papel é mais importante que o seu trabalho. Não querem saber de qualidade, querem planilhas. (UBS 7).

Os ACS vivem em uma permanente tensão e disputa entre o agir de seu trabalho vivo em ato e o trabalho morto. O trabalho vivo em ato é definido ${ }^{13}$ como atividade de trabalho cotidiana, realizado em ato, trabalho criador, inventivo, que está em ação e que opera em ambiente da micropolítica, mais centrado em tecnologias relacionais (tecnologias leves) e de conhecimento dos trabalhadores empregados no trabalho (tecnologias leve-duras). Já o trabalho morto opera de forma mais normativa, aprisionado pela lógica instrumental, com preeminência do modelo biomédico e burocrático, concentrado no uso de tecnologias duras, aquelas inscritas nas máquinas, instrumentos, normas e estruturas organizacionais ${ }^{\mathbf{2 6}}$.

A opção, na 'grande política', por um processo de trabalho mecânico, acrítico e repetitivo para o ACS tende a enquadrar um potencial trabalho vivo dos ACS - como espaço para a interação e escuta das necessidades das pessoas e comunidades -, modelando-o progressivamente para uma lógica do trabalho morto. Por tal lógica, o ACS vai paulatinamente transformando-se em um coletor e registrador de dados, cumpridor de tarefas e roteiros preestabelecidos, de modo que seu potencial de educador popular vai sendo suprimido ou despotencializado diante de um produtivismo cobrado, em cascata, pelos vários níveis de gestão do SUS: do município ao Ministério da Saúde.

\section{ACS como coprodutor da unidade}

Os ACS têm que se haver o tempo todo com a disparidade entre o trabalho prescrito e o trabalho real27. Ao operar na micropolítica, lidando com as complexas tramas de relações com a comunidade e com a singularidade das famílias e suas necessidades, os ACS, por vezes, abrem brechas na normatividade do trabalho, ajustam as regras gerais aos casos particulares, burlam prescrições, forjam sua autonomia e produzem cuidado.

Os ACS interferem no modo de funcionamento da UBS por meio de suas práticas e sentidos que dão para o trabalho. Cotidianamente, eles contribuem, com os usuários e suas necessidades, para a remodelação dos fluxos de modo informal e invisível, modificando regras de acesso, produzindo, micropoliticamente, agires que nem sempre são detectáveis e, de algum modo, aproveitados, em sua potência, pela gestão formal.

Chegamos à casa de uma usuária que perguntou pelo médico. Ela comenta que o seu marido está com uma grave infecção na perna, que já tinha ido à unidade tentar marcar e que não conseguiu consulta com brevidade. A ACS orienta a usuária: 'Não vai na recepção não, se você for na recepção você bate e volta. Chega na unidade e vai direto no consultório da enfermeira, mostra para ela e peça para ela marcar uma consulta com a médica de outra equipe com urgência. Mas não fala que eu te falei isso, viu?'. (VD com uma ACS - UBS 7).

A coprodução da UBS pelos ACS é forjada a partir de um lugar extrainstitucional, evocado por um outro ímpeto - o de querer cuidar, o de 
se preocupar com o outro, a depender da relação que estabelecem com a comunidade/usuários e das afetações que este encontro provoca.

Os ACS, dessa forma, podem executar o seu trabalho de forma burocrática, simplista, transmitindo informações biomédicas e de funcionamento do serviço mecanicamente, ou desenvolver ações cuidadoras, ouvindo as famílias com escuta qualificada e buscando soluções para seus problemas. Esses dois modos de estar e de operar no território não são excludentes, podem acontecer de forma concomitante no processo de trabalho, em uma permanente produção. "Esse suposto contraditório demarca sua rotina de trabalho, sendo que o ACS se encontra no centro de tensão entre as duas lógicas" 28.

\section{A gestão do trabalho do ACS e as re- lações de subalternidade na equipe}

A valorização social dos diferentes trabalhos na saúde é desigual, e esta desigualdade se traduz em hierarquia, relações de poder e dominação na gestão do seu trabalho ${ }^{29}$, operadas, muitas vezes, por meio de disciplinamento e controle. Essa é uma face do poder na organização que não se expressa tão explicitamente nos organogramas formais, mas atravessa a organização - no caso específico, a UBS -, em sua totalidade e em todas as direções; e, no caso dos ACS, ainda mais.

Os ACS realizam atividades e ocupam o lugar que o restante da equipe não quer, recaindo para eles o ônus de ter que fazer o que os outros membros da equipe se negam, mesmo que isso custe o atraso na realização de suas tarefas 'próprias', com menores possibilidades de dizer não às solicitações que lhes são dirigidas.

Além disso, é possível perceber também uma deslegitimação ou uma desautorização em relação ao trabalho dos ACS por parte de alguns membros da equipe: ACS desabafa em reunião de equipe

Semana passada uma colega passou por uma decepção muito grande: falou para um cadastrado dela procurar o acolhimento, pois ele estava com um problema sério... o médico falou assim: 'Quem é essa ACS? Quem é ela pra mandar alguém aqui?' (UBS 5).

Registros como esse evocam as seguintes perguntas: qual é o lugar que os ACS ocupam na equipe? Como têm sido construídas as relações de trabalho entre eles e os outros profissionais da ESF? Os ACS sentem-se parte ou à parte da equipe? $\mathrm{O}$ frequente relato dos pesquisadores em seus diários de campo sobre a disposição física dos ACS durante as reuniões, sempre juntos, mas separados do restante da equipe e, muitas vezes, quando em círculo sentados do lado de fora, como se fosse um círculo externo, pode ajudar a ilustrar essa problemática.

\section{Movimentos de resistência e inventividade}

Na permanente tensão e disputas cotidianas entre saberes e poderes na ESF, os ACS também vão inventando modos de 'encontrar' seu lugar na equipe. Existe uma forma específica de inteligência nos processos psíquicos mobilizados nos trabalhadores por meio da inovação, invenção, ajustamentos e customização do trabalho real, a 'inteligência astuciosa'27.

Tal inteligência atua como uma defesa para lidar com o trabalho real, e tem um componente transgressivo, encontrando-se em constante ruptura com as regras e normas instituídas, tendo como função a atenuação do sofrimento e a obtenção de prazer no trabalho.

Os trabalhadores constroem verdadeiras 'regras do trabalho' ou de 'ofício' que não estão de acordo com a organização oficial do trabalho. Não se trata apenas de macetes, de truques e de habilidades pontuais e isoladas, mas de uma articulação coerente entre elas, cuja soma conduz à elaboração de verdadeiros princípios reguladores para a ação e para a gestão das dificuldades ordinárias e extraordinárias observadas no curso do trabalho ${ }^{27(133) .}$ 
Entre as inúmeras prescrições postas no trabalho que estabelecem um 'deve ser', os ACS vão inventando modos de funcionamento do cotidiano, criando estratégias que fortalecem os vínculos, produzem alianças e promovem maior sentido ao trabalho.

\section{Conclusões}

O ACS é reconhecido como tendo um papel privilegiado no SUS, em particular pelo fato de ser aquele que mais convive e conhecem as condições de vida da população, aspecto central para pensar integralidade e equidade do cuidado. No entanto, embora seja fundamental o reconhecimento de sua importância no SUS, faz-se necessário compreender que a sua simples inserção na equipe de saúde, como parte da implantação da ESF, não resulta necessariamente na mudança do modelo assistencial ${ }^{30}$ caso não seja acompanhada de estratégias locais de gestão, em particular, de educação continuada/permanente, acompanhamento e avaliação do seu trabalho.

Foi possível compreender, neste estudo, que o ACS se constrói ou se produz como trabalhador da saúde com sua práxis e, a partir das relações que ele estabelece com a política, com o serviço, com a equipe e com a comunidade, em que estão em jogo os saberes, os poderes e os afetos, dimensões constitutivas da micropolítica do trabalho em saúde. O ACS, para além das responsabilidades que lhe são atribuídas pela 'grande política', é um trabalhador em permanente produção na rede de relações formais e informais que vai produzindo com seu labor.

Como aspecto positivo do artigo, pode-se destacar o fato de fazer uso de material empírico de pesquisa realizada em três municípios diferentes, o que permitiu captar múltiplas dimensões da prática do ACS. Como sua debilidade, talvez possa ser apontado o fato de os municípios estudados serem de médio e grande porte, de modo que, decerto, os resultados fossem diferentes se a pesquisa fosse realizada em pequenos municípios, ou em outras regiões do País, onde tais trabalhadores acabam assumindo funções ainda mais importantes para o cuidado.

De todo modo, analisando de forma mais abrangente, os ACS, como agentes do Estado atuam em territórios complexos, buscando apoiar a ampliação de acesso e universalidade, diretrizes caras ao SUS. Para isso, suas atribuições e habilidades precisam ser pautadas nas necessidades locais, demandando deste trabalhador uma estreita relação entre demanda, necessidade e oferta. Uma tarefa muito mais complexa do que se supunha inicialmente, exigindo que ele (re)invente sua realidade de trabalho cotidianamente. As normativas macropolíticas impostas para a sua função são insuficientes para lidar com as múltiplas dimensões micropolíticas do seu trabalho no território, onde forjam sua autonomia e autogoverno.

O que esta investigação capta é que a aposta de que a atuação do ACS permitiria uma ampliação do olhar sobre o território, reconhecendo a complexidade e fortes elementos de determinação social presentes nos processos saúde-doença - o que, em princípio, poderia reorientar o modelo de atenção -, não se realiza exatamente conforme sua formulação.

Existe uma expectativa posta no ACS de uma transformação do modelo assistencial vinculada ao conceito de território. Não é à toa que sua tarefa primordial é o cadastramento das famílias. Nesse cadastramento, ele acessa 'por dentro' a comunidade, podendo, em princípio, construir verdadeiros mapas de vulnerabilidade que poderiam ser utilizados pela equipe para o planejamento do cuidado. No entanto, muitas vezes, ele tem dificuldade na relação com a equipe; e o cadastramento acaba se tornando ritualístico e burocratizado, de algum modo reproduzindo a lógica da medicina ao ocupar boa parte do seu tempo de trabalho para marcar consulta, levar resultados de exame etc.

Esses trabalhadores têm sido cada vez mais pressionados no trabalho para a realização de procedimentos ligados ao manejo clínico de doenças, e o tempo necessário para a articulação de um trabalho de base mais comunitária vai sendo espremido pelas demandas da 
gestão, especialmente voltadas para as metas de produção que orientam o trabalho da ESF de forma produtivista e racionalizada.

Os planos de visibilidade produzidos na investigação puderam evidenciar como, no trabalho em saúde, e no do ACS, em particular, não se controlam todos os recursos, nem tudo é previsível, existem contingências, existe a subjetividade dos usuários, o que demanda um forte elemento de criatividade dos trabalhadores, experimentando novas práticas, reinventando e atualizando continuamente as políticas oficiais. Conhecer melhor o trabalho do ACS pode contribuir para que os gestores e gerentes desenvolvam estratégias que se abram para a potencial qualificação que ele pode trazer para a equipe de saúde, entre outras coisas, ao contribuir para a produção de mapas de vulnerabilidade da comunidade que, apropriados pelas equipes de forma mais consistente, possam colaborar para o aprimoramento dos cuidados primários em saúde.

\section{Colaboradores}

Barros LS (0000-0001-6320-4308)* e Cecílio LCO (0000-0002-9207-4781)* contribuíram igualmente na elaboração do manuscrito.

\section{Referências}

1. Brasil. Ministério da Saúde. Política Nacional de Atenção Básica. Brasília, DF: MS; 2012.

2. Brasil. Ministério da Saúde. O trabalho do agente comunitário de saúde. Brasília, DF: MS; 2009.

3. Gomes KO, Cotta RMM, Mitre SM, et al. O agente comunitário de saúde e a consolidação do sistema único de saúde: reflexões contemporâneas. Physis. 2010; $20(4): 1143-1164$.

4. Nunes MO, Trad LB, Almeida BA, et al. O agente comunitário de saúde: construção desse personagem híbrido e polifônico. Cad. Saúde Pública 2002; 18(6):1639-46.
5. Queirós AAL, Lima LP. A institucionalização do trabalho do agente comunitário de saúde. Trab Educ Saúde. 2012; 10(2):257-81.

6. Portal do Departamento de Atenção Básica: Cobertura de SF. [acesso em 2017 dez 26]. Disponível em: http://dab.saude.gov.br/portaldab/historico_cobertura_sf.php.

7. Brasil. Ministério da Saúde. Portaria no 2.436, de 21 de setembro de 2017. Aprova a Política Nacional de Atenção Básica, estabelecendo a revisão de diretrizes para a organização da Atenção Básica, no âmbito do Sistema Único de Saúde (SUS). Diário Oficial da União. 22 Set 2017.
*Orcid (Open Researcher and Contributor ID). 
8. Associação Brasileira de Saúde Coletiva; Centro Brasileiro de Estudos de Saúde; Escola Nacional de Saúde Pública Sergio Arouca. Contra a reformulação da PNAB - nota sobre a revisão da Política Nacional de Atenção Básica 2017 [internet]. Rio de janeiro: Notas Oficiais da Abrasco; 2017 [acesso em 2018 fev 2]. Disponível em: https:// www.abrasco.org.br/site/noticias/posicionamentos-oficiais/contra-reformulacao-da-pnab-nota-sobre-revisao-da-politica-nacional-de-atencao-basica/29798/.

9. Albarello L, Digneffes F, Hiernaux J, et al. Práticas e métodos de investigação em ciências sociais. Lisboa: Gradiva; 2000.

10. Mercado F, Gastaldo D, Calderon C, organizadores. Paradigmas y diseños de la investigación cualitativa en salud. Jalisco: Universidade de Guadalajara Coordinácion Editorial; 2002.

11. Turato E. Tratado da metodologia da pesquisa clínico-qualitativa: construção teórico-epistemológica, discussão comparada e aplicação nas áreas da saúde e humanas. Petrópolis: Vozes; 2003.

12. Melucci A. Por uma sociologia reflexiva. Pesquisa qualitativa e cultura. Petrópolis: Vozes; 2005.

13. Merhy EE. Saúde: a cartografia do trabalho vivo. 3. ed. São Paulo: Hucitec; 2007.

14. Lapassade G. As microssociologias. Brasília, DF: Liber Livro; 2005.

15. Passos E, Kastrup V, Escócia L. Pistas do método da cartografia: pesquisa-intervenção e produção de subjetividade. Porto Alegre; 2009.

16. Passos E, Kastrup V, Tedesco S, editores. Pistas do método da cartografia: a experiência da pesquisa e o plano comum. Porto Alegre: Sulina; 2014. (v. 2).

17. Ferigato SH, Carvalho SR. Pesquisa qualitativa, cartografia e saúde: conexões. Interface - Comun Saúde Educ. 2011; 15(38):663-76.
18. Costa SL, Carvalho EN. Agentes Comunitários de Saúde: agenciadores de encontros entre territórios. Ciênc Amp Saúde Coletiva. 2012; 17(11):2931-40.

19. Fortes PAC, Spinetti SR. O agente comunitário de saúde e a privacidade das informações dos usuários. Cad. Saúde Pública. 2004; 20(5):1328-33.

20. Mendonça MHM. Agente comunitário de saúde: o ser, o saber, o fazer. Cad. Saúde Pública. 2004; 20(5):1433-4.

21. Nogueira RP, Silva FB, Ramos ZVO. Vinculação Institucional de um Trabalhador Sui Generis - O Agente Comunitário de Saúde. Brasília, DF: IPEA; 2000.

22. Costa SM, Araújo FF, Martins LV, et al. Agente Comunitário de Saúde: elemento nuclear das ações em saúde. Ciênc. Saúde Colet. 2013; 18(7):2147-56.

23. Jamra CCA, Cecílio LCO, Correia T. Os médicos e a racionalização das práticas hospitalares: novos limites para a liberdade profissional? Saúde debate. 2016; 40(108):86-94.

24. Vieira MMF, Oliveira LMB, organizadores. Administração Contemporânea: perspectivas estratégicas. Rio de Janeiro: Atlas; 1999.

25. Correia T. Medicina: o agir numa saúde em mudança. Lisboa: Mundos Sociais; 2012.

26. Ferreira VSC, Andrade CS, Franco TB, et al. Processo de trabalho do agente comunitário de saúde e a reestruturação produtiva. Cad. Saúde Pública. 2009; 25(4):898-906.

27. Dejours C, Abdoucheli E. Itinerário teórico em psicopatologia do trabalho. In: Jayet C, Dejours C, Abdoucheli E, et al. Psicodinâmica do trabalho: Contribuições da Escola Dejouriana à análise da relação prazer, sofrimento e trabalho. São Paulo: Atlas; 1994. p. 119-45.

28. Ferreira VSC. Micropolítica do processo de trabalho do agente comunitário de saúde (ACS): território de produção de cuidado e subjetividade [tese]. 
Rio de Janeiro: Universidade Federal do Rio de Janeiro; 2008. 299 p.

29. Galavote HS. Alegrias e tristezas no cotidiano de trabalho do Agente Comunitário de Saúde: cenários de paixões e afetamentos. Interface (Botucatu). 2010; 17(46):575-586.

30. Bornstein VJ, Matta GC, David H. O processo de tra- balho do agente comunitário de saúde e sua incidência sobre a mudança do modelo de atenção em saúde. In: Monken M, Dantas AV, editores. Estud. Politécnica E Saúde. Rio de Janeiro: EPSJV; 2009. p. 191-219.

Recebido em 23/01/2019

Aprovado em 23/05/2019

Conflito de interesses: inexistente

Suporte financeiro: não houve 